\title{
Foreword
}

This volume presents a series of penetrating essays on Brazil's economic development during the postwar period by a group of exceptionally well-informed Brazilian and American authors. It reaches more deeply into key aspects of a transitional economy than much of the literature on developing countries which deals only with broad macro-economic aggregates. The Brazilian authors include professional economists who have been at the center of national policy formation and execution, as well as some of the best trained representatives of the younger generation. On the American side, all the contributors have had the benefit of intimate contact with the complexities of Brazilian economic life.

The postwar decades have been a period of dramatic change in the Brazilian economy, marked by rapid industrialization, urbanization, inflation sometimes approaching monetary chaos, and a kaleidoscopic overlay of shifting political forces. The old cliché of the "sleeping giant," with an everreceding potential for a never-realized future, has totally disappeared. These have been years of early adolescence in Brazil's struggle for economic maturity, and the imbalances and growing pains of adolescence are still much in evidence. There remain immense challenges in the needs for institutional modernization in agriculture and education, the efficient diversifcation of export products and markets, and the simulation of investment and job creation to match the heavy pressures of demographic growth and migration to the cities.

Nevertheless, the Brazilian economy is clearly in motion, 
even though its destiny remains uncertain. These essays should help both professional economists and the wider public to understand some of the processes and problems being faced in deciding that destiny.

\section{LINCOLN GORDON}

President, The Johns Hopkins University, U.S. Ambassador to Brazil, 1961-1966 